ARTIGO

\title{
Deficiência visual: caminhos legais e teóricos da escola inclusiva
}

\author{
Fabiane Maia Garcia ${ }^{a}$ \\ Aissa Thamy Alencar Mendes Braz b
}

\section{Resumo}

$\mathrm{O}$ artigo apresenta resultados de uma pesquisa sobre a cegueira e a baixa visão no contexto da democratização do acesso e permanência escolar. Parte dos aspectos históricos e legais, que marcam os caminhos da política pública da área, a partir do mote da análise da cegueira, com foco na acessibilidade, pois as categorias da deficiência visual e outras questões da inclusão demandam especificidades que, no momento, não aprofundamos. Por ser uma pesquisa exploratória, os resultados partem de uma densa pesquisa bibliográfica em livros e artigos que contribuíram para a compreensão em torno da temática. Desse modo, identificaram-se as demandas formais e legais que existem para garantir o acesso e a permanência nas escolas, assim como as condições estruturais necessárias para esse atendimento, com um quadro de sua legislação básica. O estudo também reúne algumas informações da Secretaria de Educação Municipal de Manaus, que iniciou a partir de 2017 um mapeamento da estrutura escolar voltada para a acessibilidade. Os dados catalogados da estrutura física existente nas escolas, e disponibilizados pelo setor de engenharia da Secretaria, evidenciam a complexidade em torno das questões teóricas e práticas no contexto democrático que supõe a substituição da concepção de escola exclusiva para o de escola inclusiva, em relação ao atendimento do aluno com deficiência visual.

Palavras-chave: Acessibilidade. Deficiência Visual. Escola Exclusiva. Escola Inclusiva.

\section{Introdução}

O presente artigo discute três questões a partir dos pressupostos da democratização de acesso, da permanência e da inclusão no contexto da escola pública em Manaus. A primeira questão apresenta o processo histórico no que se refere à pessoa

\footnotetext{
a Universidade Federal do Amazonas, Manaus, AM, Brasil.

b Universidade Federal do Amazonas, Manaus, AM, Brasil.

Recebido em: 01 jul. 2019

Aceito em: 20 fev. 2020
} 
com deficiência visual. A segunda retrata as previsões legais para recursos de acessibilidade para o público em debate, com qualificações previstas. A terceira está marcada pela forma como a escola, em Manaus, tem buscado migrar do conceito de escola exclusiva para o da escola inclusiva, como categorias criadas para a análise dos dados da pesquisa. Na formulação, há destaque para uma composição teórica e analítica, que resultou, em sua maioria, de consultas a fontes disponíveis em formato eletrônico e pesquisas com base na Lei de Acesso à Informação ${ }^{\circ}$ 12.527, de 18 de novembro de 2011 (BRASIL, 2011), que regulamenta o direito constitucional dos cidadãos a obterem informações públicas, seja da União, dos Estados, do Distrito Federal ou dos Municípios.

O princípio democrático do acesso é um direito garantido pela Constituição Federal de 1988, nos Art. 205, 206 e 208 (BRASIL, 1988), que assegura aos estudantes com necessidades específicas acesso a uma Educação de qualidade. Nesse caso, não basta assegurar a matrícula nas escolas, mas garantir atendimento especializado que possibilite o desenvolvimento de todas as potencialidades do estudante.

Em relação à especificidade do estudo, identificamos que, no Brasil, cerca de $20 \%$ da população têm deficiência visual, de acordo com o Instituto Brasileiro de Geografia e Estatística - IBGE, em pesquisa realizada em 2010. Esse dado apresenta a deficiência visual como a maior de todas no âmbito das deficiências, com a seguinte classificação: $1^{\circ}$ Deficiência Visual, $2^{\circ}$ Deficiência Auditiva, $3^{\circ}$ Deficiência Motora e $4^{\circ}$ Mental ou Intelectual (BRASIL, 2012).

Para iniciar o estudo sobre os direitos dos estudantes com deficiência visual em relação à oferta educativa, fatores como condições estruturais previstas na legislação e no conjunto teórico já consolidado são fundamentais. Com base na relação legal e teórica, orientam-se técnicas e práticas necessárias para que os profissionais na escola possam receber e atender o público em questão, viabilizando condições para que a perspectiva de escola inclusiva se efetive.

\section{Aportes legais e teóricos}

O estudo busca contemplar os aspectos necessários para a inclusão escolar, com análise das políticas públicas que asseguram o processo de Ensino-aprendizagem às crianças com necessidades específicas. Objetivou-se identificar as demandas formais e legais que existem para garantir o acesso e a permanência nas escolas, assim como as condições estruturais, necessárias ao atendimento. Desse modo, o texto analisa o conjunto da legislação, da teoria e dos dados obtidos, que, quando comparados, evidenciam o contexto escolar em relação ao atendimento 
com recursos de acessibilidade específicos para pessoas com deficiência visual. O texto também se esforça em apresentar as condições físicas, técnicas e profissionais que devem ser oferecidas pela escola, a partir da configuração da legislação, das categorias e dos referenciais adotados na análise escolhida, nomeadamente a cegueira.

A Educação está inserida nos processos históricos, socioeconômicos, políticos e culturais da sociedade. Por um longo período da história, a Educação não foi pensada formalmente para o atendimento a estudantes com deficiência. Isso porque eles eram vistos por dois lados: os que expressavam caridade e os rejeitados que estavam em pecado. Dessa forma, muitos eram ignorados pela sociedade, até o cristianismo. Nesse momento, a Igreja mudou a concepção dos fiéis em relação ao preconceito existente naquela época ao apontar que todos eram filhos de Deus. Assim, com a expansão do cristianismo, as pessoas com deficiência não eram mais, necessariamente, abandonadas, e logo surgiram os atendimentos assistenciais, dentro de igrejas ou asilos (MASINI, 1994). Analisando outras leituras e a realidade cotidiana, é possível conjecturar essa inclusão a partir de duas hipóteses: a primeira, ligada a uma exclusão familiar, pois ao ter a obrigação de vincular um de seus membros ao clero, a família enviava o deficiente. A segunda hipótese relacionava-se à própria condição do deficiente que necessitava de maior atenção e cuidados, incluindo a própria alimentação, condição mais apropriada no interior dos espaços religiosos.

Em um contexto em que prevalecia a ideia do deficiente como pessoa castigada por Deus e culpada por sua condição, os deficientes eram facilmente encaminhados a asilos e abrigos, locais onde alimentação e moradia eram oferecidas, com exigências religiosas, éticas e força de trabalho. Conforme Mosquera (2010), ao longo do tempo, nas diversas regiões do mundo, as pessoas com deficiência tiveram diferentes significados aos olhos da sociedade em que estavam inseridas. Infelizmente, essa forma de lidar com a deficiência resultou na exclusão, no associar negativo, gerando aversão, criando uma cultura de discriminação.

A busca de normativos em endereços eletrônicos especializados indica, no Brasil Imperial ${ }^{1}$, o período dos primeiros registros legais sobre a temática. Em 1835, o deputado Cornélio Ferreira, da Bahia, apresentou um projeto de lei com o objetivo de levar para cegos e surdos o Ensino das primeiras letras. Porém, esse projeto foi arquivado e somente em 1845 surgiu o Ensino para deficientes visuais, que só poderiam ter acesso à Educação se a escola estivesse de acordo em recebê-los,

A partir dos referenciais consultados não foi possível constituir uma perspectiva histórica mais detalhada sobre como era tradado o deficiente no Brasil colonial. 
pois a constituição da época não reconhecia a obrigatoriedade de inclusão aos educandos com necessidades específicas.

Para Masini (1994), no Brasil, o primeiro olhar que se teve para as pessoas com deficiência visual foi em 12 de setembro de 1854, quando o Imperador Pedro II baixou o Decreto Imperial, criando o Imperial Instituto de Meninos Cegos (BRASIL, 1854). Logo após o advento da república, esse instituto passou a denominar-se Instituto Benjamin Constant (IBC), sendo a única instituição da época encarregada da Educação dos deficientes visuais.

Com o passar dos anos, o cenário foi modificando-se e o movimento Escola Nova trouxe consigo o objetivo da renovação do Ensino, partindo do princípio da autonomia e da liberdade de cada criança, defendendo a universalização do Ensino. Assim, somente em 1946 os recursos didáticos começaram a ser adaptados no Brasil, quando livros em braile foram impressos, proporcionando condições de estudo mais adequadas. Em 1950, a primeira turma de braile foi inaugurada em São Paulo, em uma escola de Ensino regular. Aos poucos, foram surgindo campanhas que objetivavam ampliar o atendimento para os deficientes visuais no território nacional, de forma a fornecer subsídios técnicos e financeiros, incentivando as organizações de cursos especiais e proporcionando a fundação de entidades educacionais (ANACHE, 1994).

Mosquera (2010) cita outro passo importante para a conscientização em prol das pessoas com deficiência, que foi a Declaração Mundial, ocorrida em Salamanca, na Espanha, no período de 07 a 10 de Junho de 1994 (CONFERÊNCIA MUNDIAL DE EDUCAÇÃO ESPECIAL, 1994), com 88 governos, mais 25 organizações internacionais, com apoio da Organização das Nações Unidas para a Educação, a Ciência e a Cultura (Unesco), do Fundo nas Nações Unidas para a Infância (Unicef) e do Programa das Nações Unidas para o Desenvolvimento (UNDP), tendo como foco principal o debate e a discussão da inclusão e integração de pessoas com necessidades especiais em escolas regulares, buscando combater a discriminação.

No Brasil, é notória a importância da Constituição Federal de 1988, Artigo 208 (BRASIL, 1988), em que se estabelece o dever do Estado na efetivação de medidas que garantam o atendimento educacional especializado aos portadores de deficiência ${ }^{2}$, preferencialmente na rede não exclusiva de Ensino, ou seja, em toda e qualquer escola.

\footnotetext{
O termo "Portador de deficiência" permeou até a década de 1990, sendo modificado em 03 de novembro de 2010 pela Portaria no 2.344/2010 da Secretaria dos Direitos Humanos, para a nomenclatura "pessoas com deficiência". Essa nova expressão surgiu inicialmente na Declaração de Salamanca. Disponível no site: http://portal.mec.gov.br/seesp/arquivos/pdf/salamanca.pdf
} 
Outras mudanças também surgiram, como a criação da Política Nacional de Educação Especial, em 1994 (BRASIL, 1994), com intuito de incentivar toda e qualquer escola a ser inclusiva para atendimento a crianças com deficiência, proporcionando apoio às escolas que estivessem dispostas a integrar. É significativo também saber que a Lei de Diretrizes e Bases da Educação nº 9394/96, no Artigo 5, busca incentivar a garantia de atendimento aos alunos com deficiência, preferencialmente na escola regular, mencionando a oferta do Atendimento Educacional Especializado, que é um serviço da Educação Especial, que veio para dar suporte ao processo de escolarização dos alunos público-alvo da Educação Especial nas escolas de Ensino regular, identificadas doravante como escolas inclusivas (BRASIL, 1996).

O Decreto $\mathrm{n}^{\circ}$ 5296, de 02 de dezembro de 2004 (BRASIL, 2004), veio, então, para regulamentar a Lei ${ }^{\circ} 10.048$, de 08 de novembro de 2000, que dá prioridade no atendimento às pessoas que especifica, e a Lei no 10.098, de 19 de dezembro de 2000 (BRASIL, 2000), que estabelece normas gerais e critérios básicos para a promoção da acessibilidade para pessoas com deficiência ou com mobilidade reduzida. Além disso, dá outras providências, como a instalação de piso tátil direcional e de alerta em espaços públicos ou privados.

Por conseguinte, é importante também citar a Resolução CNE/CEB n ${ }^{\circ} 04$ de 2009 que trata das diretrizes operacionais para o Atendimento Educacional Especializado. Em seu Art. $2^{\circ}$, determina sua função como meio complementar ou suplementar para a formação do aluno, através da disponibilização de serviços, recursos de acessibilidade e de estratégias que eliminem as barreiras para sua plena participação na sociedade e para o desenvolvimento de sua aprendizagem.

Em 17 de novembro de 2011, o Decreto $\mathrm{n}^{\circ} 7611$ determinou pontos relevantes voltados para a Educação Especial, baseados no atendimento especializado, visando à integração e à universalização do Ensino para todos, respeitando também as limitações de cada um, garantindo adaptações no Ensino e proporcionando ofertas de vagas no Ensino regular.

Por fim, recentemente, o Plano Nacional de Educação - PNE, que compreende o decênio 2014-2024, estabeleceu 20 metas, e a meta 4 volta-se para o atendimento da pessoa com algum tipo de deficiência, altas habilidades ou superdotação, mas omite questões relacionadas a outras formas de inclusão escolar, como, por exemplo, às questões referentes às diferenças étnicas. Contudo, segundo Macena, Justino e Capelline (2018, p. 1290), "essa meta é a que mais se aproxima da formalização do Ensino baseado numa Cultura Inclusiva, que visa acima de tudo ao atendimento a todos os cidadãos, independentemente de qualquer característica que os diferencie dos demais". 
Para facilitar o entendimento dos normativos brasileiros, segue abaixo o Quadro 1 com outras legislações complementares, e em ordem cronológica.

Quadro 1 - Constitutivo legal das previsões de atendimento ao deficiente visual

\begin{tabular}{|c|c|}
\hline Legislação & Regulamento \\
\hline $\begin{array}{l}\text { Decreto } n^{\circ} 1.428 \text {, de } 12 \\
\text { de setembro de } 1854\end{array}$ & Regulamento provisório do Imperial Instituto dos Meninos Cegos. \\
\hline $\begin{array}{l}\text { Decreto } 51.045 \text {, de } 26 \\
\text { de julho de } 1961\end{array}$ & $\begin{array}{l}\text { Foi instituído, oficialmente, o Dia do Cego, sendo comemorado } \\
\text { nacionalmente em } 13 \text { de dezembro. }\end{array}$ \\
\hline $\begin{array}{l}\text { Lei } n^{\circ} 4.169 \text {, de } 4 \text { de } \\
\text { dezembro de } 1962\end{array}$ & $\begin{array}{l}\text { Oficializa as convenções Braille para uso na escrita e leitura dos } \\
\text { cegos e o Código de Contrações e Abreviaturas Braille. }\end{array}$ \\
\hline $\begin{array}{l}\text { Lei } n^{\circ} 10.048 \text {, de } 8 \text { de } \\
\text { novembro de } 2000\end{array}$ & $\begin{array}{l}\text { Dá prioridade de atendimento às pessoas que especifica, e dá } \\
\text { outras providências. }\end{array}$ \\
\hline $\begin{array}{l}\text { Resolução } n^{\circ} 2 \text {, de } 11 \\
\text { de setembro de } 2001\end{array}$ & $\begin{array}{l}\text { Institui Diretrizes Nacionais para a Educação Especial na Educação } \\
\text { Básica. }\end{array}$ \\
\hline $\begin{array}{l}\text { Lei } n^{\circ} 10.753 \text {, de } 30 \text { de } \\
\text { outubro de } 2003\end{array}$ & $\begin{array}{l}\text { Institui a Política Nacional do Livro. Inclusive, assegura às pessoas } \\
\text { com deficiência visual o acesso à leitura, por meio de livros } \\
\text { impressos no Sistema Braille. }\end{array}$ \\
\hline $\begin{array}{l}\text { Lei } n^{\circ} 10.845 \text {, de } 5 \text { de } \\
\text { março de } 2004\end{array}$ & $\begin{array}{l}\text { Institui o Programa de Complementação ao Atendimento } \\
\text { Educacional Especializado às Pessoas Portadoras de Deficiência, e } \\
\text { dá outras providências. }\end{array}$ \\
\hline $\begin{array}{l}\text { Lei } n^{\circ} 11.126 \text {, de } 27 \text { de } \\
\text { junho de } 2005\end{array}$ & $\begin{array}{l}\text { Dispõe sobre o direito do portador de deficiência visual de } \\
\text { ingressar e de permanecer em ambientes de uso coletivo } \\
\text { acompanhado de cão-guia. }\end{array}$ \\
\hline $\begin{array}{l}\text { Lei no } 11.982 \text {, de } 16 \text { de } \\
\text { julho de } 2009\end{array}$ & $\begin{array}{l}\text { Acrescenta parágrafo único ao art. } 4 \text { o da Lei no } 10.098 \text {, de } 19 \text { de } \\
\text { dezembro de } 2000 \text {, para determinar a adaptação de parte dos } \\
\text { brinquedos e dos equipamentos de parques de diversões às necessidades } \\
\text { das pessoas com deficiência ou com mobilidade reduzida. }\end{array}$ \\
\hline $\begin{array}{l}\text { Lei } n^{\circ} 13.146 \text {, de } 6 \text { de } \\
\text { julho de } 2015\end{array}$ & $\begin{array}{l}\text { Institui a Lei Brasileira de Inclusão da Pessoa com Deficiência } \\
\text { (Estatuto da Pessoa com Deficiência). }\end{array}$ \\
\hline
\end{tabular}

Fonte: Elaborado pelas autoras a partir dos dados obtidos no site do Planalto e da Câmara dos Deputados, 2017 (2019)

O vasto campo normativo apresentado não implicou, necessariamente, em atendimento imediato ou qualitativo dos direitos e das garantias previstas. Tão importante quanto a legislação, tem sido a construção teórica que debate, fundamenta e questiona a realidade educativa em relação ao atendimento de estudantes que apresentam deficiência, transtornos globais do desenvolvimento e altas habilidades ou superdotação.

Teoricamente, Sá, Silva e Simão (2010) definem a deficiência visual como o conjunto de alterações que podem ser relativamente simples, passíveis de correções 
por meio de auxílios ópticos ou cirurgia, até graves degenerações, atrofias ou lesões oculares que podem culminar com a cegueira.

Em vista disso, na deficiência visual, vamos ter duas categorias: a cegueira e a baixa visão. Para Sá, Campos e Silva (2007), a cegueira é uma alteração grave ou total da visão, afetando a capacidade de perceber cor, tamanho, distância, forma, posição ou movimento. Já a baixa visão é uma grave perda visual, ou seja, é a redução da acuidade visual. Nesse caso, ainda existem resquícios de visão. Assim, a cegueira pode ser apresentada desde o nascimento (cegueira congênita) ou em decorrência de causas orgânicas ou acidentais (cegueira adventícia-adquirida).

Bruno (2006) enfatiza que a deficiência visual, por si só, não acarreta dificuldades cognitivas, emocionais e de adaptação social. Ou seja, são as interações, comunicações e significados socialmente construídos que irão determinar o processo de desenvolvimento, aprendizagem e adaptação social das crianças. É na escola que a criança cega irá construir suas primeiras relações sociais fora do âmbito familiar.

Costa (2012) destaca que, durante muito tempo, nossa escola tem se configurado como excludente e, por conseguinte, conservadora, principalmente, por privilegiar aqueles tidos como bons, perfeitos e normais. Também afirma que um dos maiores desafios da escola inclusiva é lutar para eliminar as barreiras que impedem o livre acesso de todos ao conhecimento. Dentre as que precisam ser eliminadas, as principais são as barreiras atitudinais: preconceitos, estigmas e discriminação, e as barreiras arquitetônicas: obstáculos que impedem o acesso e uso dos ambientes, sejam eles coletivos ou individuais.

\section{Caminhos e opções metodológicas de uma pesquisa}

A pesquisa processou-se com base em uma disciplina em 2016 e formalizou-se em um projeto de iniciação científica no primeiro semestre de 2018. Desse modo, no segundo semestre de 2016, por meio da disciplina Projeto de Pesquisa I, na Universidade Federal do Amazonas, foi pensado o projeto que se configurou em dados e validações entre pares, durante o ano de 2017, com as disciplinas Projeto de Pesquisa II e Seminário de Pesquisa, como parte do Eixo de Pesquisa do Curso de Pedagogia da Universidade Federal do Amazonas.

Os dados resultaram de uma consulta formal ao Setor de Engenharia da Secretaria Municipal de Educação de Manaus (Semed - Manaus), com o envio de um 
questionário em formato eletrônico e, posteriormente, na análise de Relatórios de Estágios do Curso de Pedagogia ${ }^{3}$. Assim, a pesquisa que se apresenta discute os resultados das análises em fontes primárias e secundárias, além da visita ao setor da Semed, sendo possível dialogar sobre as questões que envolvem a acessibilidade das escolas de Manaus.

Outra fonte importante do processo de pesquisa foi a adesão contínua ao uso do Sistema Eletrônico do Serviço de Informação ao Cidadão (E-SIC), como no caso específico do protocolo $\mathrm{n}^{\mathrm{o}} 23480-014657 / 2017-51$, que nos possibilitou levantar o número de escolas e de alunos registrados com cegueira, no setor público e privado na cidade de Manaus, no ano de 2016.

Portanto, a pesquisa realizada pode ser classificada como exploratória, pois tem como finalidade uma maior aproximação com o problema, de forma a torná-lo mais explícito, possibilitando a construção de questões investigativas, que se ampliam a partir de cada novo resultado. Podemos dizer que o seu principal objetivo foi o aprimoramento de ideias, de forma a permitir abrir espaço para diversos aspectos relacionados ao tema estudado.

Desse modo, na descrição dos resultados há uma abordagem qualitativa, que buscou discutir questões da temática proposta. Para Minayo, Deslandes e Gomes (2015), a abordagem qualitativa ocupa-se, nas Ciências Sociais, com um nível de realidade que não pode, ou não deveria ser quantificado. Ou seja, trabalha com o universo dos significados, dos motivos, das aspirações, das crenças, dos valores e das atitudes.

\section{Resultados e discussões: de uma escola exclusiva para uma inclusiva}

Em uma busca pelo número de alunos registrados com deficiência visual, com ênfase na cegueira, junto ao E-SIC, registrado sob o protocolo ${ }^{\circ}$ 23480-014657/2017-51, foi possível organizar alguns resultados. Os dados estão dispostos a partir dos conceitos de escola exclusiva e inclusiva, cunhados para o estudo. O primeiro é parte do contexto histórico de atendimento educacional aos deficientes, em espaços diferenciados e exclusivos ou em salas de atendimento educacional especializado. O segundo contrapõe-se ao conceito de escola regular ou classes comuns, pois entendemos que toda escola se enquadra nos dois termos, pois o contrário (irregular ou incomum) não possui sustentação na política educativa

O Projeto de iniciação científica está em andamento e busca analisar os processos de atendimento aos estudantes com deficiência visual a partir dos relatórios de Estágio I e II do Curso de Pedagogia. 
brasileira. Assim, escola inclusiva deve ser toda escola que assegura o direito previsto no conjunto da legislação existente, tornando a escola um espaço democrático a todos.

Os dados obtidos correspondem a 2.057 escolas no Estado do Amazonas, abrangendo o setor público e o privado. Dessas, apenas 102 possuem alunos com cegueira matriculados. O número de matrículas na Educação Especial em escolas inclusivas e/ou EJA é de 310 alunos, segundo dados de 2016 (Quadro 2).

Quadro 2 - Número de Matrículas na Educação Especial - Escolas inclusivas e/ou EJA

\begin{tabular}{|lccc|}
\hline Instituição de Ensino & $\begin{array}{c}\text { Número total } \\
\text { de escolas }\end{array}$ & $\begin{array}{c}\text { Escolas com alunos } \\
\text { matriculados }\end{array}$ & $\begin{array}{c}\text { Alunos cegos } \\
\text { matrículados }\end{array}$ \\
\hline Escola inclusiva e EJA & 2.075 & 102 & 310 \\
\hline
\end{tabular}

EJA: Educação de Jovens e Adultos.

Fonte: Elaborado pelas autoras a partir dos dados obtidos no E-SIC, 2018 (2019)

Com relação ao número de matrículas na Educação Especial em classes exclusivas, foi realizado um levantamento de 158 escolas e o número de matrículas de alunos cegos é 233, distribuídos em 15 escolas (Quadro 3).

Quadro 3 - Número de Matrículas na Educação Especial em Escolas Exclusivas (Especializadas e/ou Classes Especiais ou Educação de Jovens e Adultos - EJA), com deficiência visual

\begin{tabular}{|lccc|}
\hline Instituição de Ensino & $\begin{array}{c}\text { Número total } \\
\text { de escolas }\end{array}$ & $\begin{array}{c}\text { Escolas com alunos } \\
\text { matriculados }\end{array}$ & $\begin{array}{c}\text { Alunos cegos } \\
\text { matrículados }\end{array}$ \\
\hline Escolas exclusivas & 158 & 15 & 233 \\
\hline
\end{tabular}

Fonte: Elaborado pelas autoras a partir dos dados obtidos no E-SIC, 2018 (2019)

É interessante perceber, em relação ao número de matrículas nas escolas inclusivas ${ }^{4}$ e nas escolas exclusivas, que, embora nas primeiras tenha-se um número um pouco maior, não há tanta expressividade se analisada a partir do número total de escolas. Assim, diante de toda a trajetória apresentada no estudo acerca das diretrizes legais e teóricas para a inclusão, boa parte dos estudantes continuam em escolas exclusivas.

Os dados que confirmam a presença de estudantes com cegueira nas escolas inclusivas indicam a necessidade de estratégias e recursos que auxiliem o 
atendimento, garantindo a permanência no âmbito escolar, a partir de ações pedagógicas desenvolvidas e da oferta de acessibilidade aos estudantes. Assim, a escola irá exercer essa função quando, primeiramente, oferecer, nesses espaços, igualdade de oportunidade, pluralidade de experiências e participação plena no âmbito escolar.

Lutar pela escola inclusiva no sistema público de Ensino é parte do combate às discriminações ainda existentes na sociedade, uma vez que todos, independentemente de suas limitações, estão assegurados pelos preceitos normativos vigentes. Como é reforçado por Marques (1997, p. 21):

Jamais haverá integração se a sociedade se sentir no direito de escolher quais deficientes poderão ser integrados. Agindo dessa forma, a sociedade estabelece um limite de possibilidades baseada no que ela entende como normal, só permitindo a inserção de quem se iguala ou se aproxima desse ideal de normalidade.

Segundo Batista et al. (2014), os dados do Complexo Municipal de Educação Especial (CMEE) indicam que, somente no município de Manaus, o número de pessoas com deficiência visual fora do âmbito escolar chega a 70\%. Do mesmo modo, os estudantes com acesso escolar não são contemplados pelos recursos adaptados e fundamentais para o processo de Ensino e de aprendizagem. Logo, é preciso retomar o princípio legal da obrigação da escola oferecer, buscar e instalar atendimento especializado. Anache (2013, p. 95) aponta que:

Mesmo aqueles estudantes com deficiência que apresentam uma condição social e econômica mais favorável possuíam dificuldades no seu processo de escolarização, justificadas pelas precárias condições de acessibilidade físicas e curriculares, agravadas pelas atitudes discriminatórias presentes nas escolas públicas e privadas deste país.

De modo geral, é possível identificar na literatura e nos dados existentes que os tipos de apoios oferecidos às crianças com deficiência visual ainda são insuficientes. Também é perceptível a necessidade de criar estratégias para uma intervenção precoce com base no desenvolvimento e na capacitação da criança, para que na fase adulta não venha a sofrer pela falta de preparo da família e da escola. Logo, uma escola inclusiva é aquela que busca evitar a exclusão, a repetência e a evasão, fatores que asseguram outros processos. 
Para a manutenção da escola inclusiva, são imprescindíveis mudanças na infraestrutura, propiciando um espaço adequado. Nesse caso, realçamos a exigência de se modificar o ambiente da sala de aula e a escola como um todo, desde a remoção de obstáculos até a utilização do piso tátil, melhorando a acessibilidade para que as crianças possam participar ativamente da vida escolar.

A sinalização tátil no piso é um recurso complementar para auxiliar na segurança, na orientação e na mobilidade do deficiente visual, conforme definido no Decreto $n^{\circ} 5296$ (BRASIL, 2004), que estabelece normas gerais e critérios básicos para a promoção da acessibilidade das pessoas com necessidades específicas. Acessibilidade é garantir a possibilidade e a condição de alcance, a percepção e o entendimento para utilização com segurança e autonomia de espaços, mobiliários, equipamentos urbanos, edificações, transportes, informação e comunicação. $\mathrm{O}$ Art. 15, parágrafo primeiro, inciso terceiro, define a: III - a instalação de piso tátil direcional e de alerta.

Além disso, a criança com deficiência visual irá interpretar e internalizar o mundo à sua volta por meio do tato, olfato e audição. Logo, é essencial garantir salas de aula adaptadas e incentivar o reconhecimento dos espaços físico e da disposição do mobiliário em sala de aula, ensinando noções básicas de orientação e mobilidade que ultrapassarão o âmbito escolar.

A realização da pesquisa motivou o Setor de engenharia da Semed a dar continuidade ao mapeamento das escolas de Manaus. Esse mapeamento tem sido realizado por meio de um levantamento cadastral das escolas de Manaus que são divididas por DDZ (Divisão Distrital Zona). Em Manaus, o acompanhamento da oferta educativa é realizado pela divisão de sete zonas: Centro-Sul, Sul, Norte, Leste-1, Leste-2, Centro-Oeste e Oeste. Dessa forma, o setor de engenharia da Semed encaminha ao gestor de cada escola um questionário, que deve ser assinalado com um " $\mathrm{X}$ " nos itens correspondentes, caso a escola possua as adequações estabelecidas (rampas, piso tátil, adaptações de sala de aula etc.).

Nesse setor, as maiores dificuldades encontradas são mapear as escolas com projetos de acessibilidade devido à falta de equipe para reunir essas informações, além da ausência de devolutiva, por parte dos gestores, das informações solicitadas pelo setor. Porém, por meio das visitas já realizadas, o setor informou que as escolas de Manaus não possuem acessibilidade. Na verdade, algumas têm projeto, mas foram planejadas e/ou construídas de forma irregular. Em realidade, as adaptações são feitas com verbas obtidas pela escola, via projeto ou doação. Cada estrutura possui uma característica própria, que, normalmente, não atende aos padrões legalmente estipulados. 
A partir de nossas solicitações, o Setor de Engenharia da Semed intensificou a coleta de informações das escolas. É importante mencionar que a Semed já possui um banco de dados organizado para coletar informações sobre a estrutura das escolas, mas foi a solicitação de informações, como parte da pesquisa, que, de algum modo, reativou o interesse pelo mapeamento. Assim, a partir da troca de e-mails e envio de um questionário, obtivemos um conjunto de informações enviado pelo Setor de Engenharia da Semed, correspondente a quatro, das sete zonas, pois, segundo os responsáveis pelo setor, as outras não deram retorno até meados de 2018 (Quadro 4).

Quadro 4 - Mapeamento de acessibilidade - Semed/Manaus

\begin{tabular}{|lccc|}
\hline Ddz & $\mathbf{N}^{\circ}$ total de escolas & $\begin{array}{c}\text { Escolas com salas } \\
\text { adaptadas }\end{array}$ & Escolas com piso tátil \\
\hline Zona norte & 68 & 28 & 04 \\
Zona sul & 69 & 10 & 04 \\
Zona centro-sul & 54 & 11 & 07 \\
Zona leste-1 & 75 & 37 & 06 \\
Total & 266 & 86 & 21 \\
\hline
\end{tabular}

Fonte: Elaborado pelas autoras a partir dos dados obtidos junto ao setor de Engenharia da Semed/Manaus, 2018 (2018)

Além das estruturas físicas, necessárias ao atendimento da criança com deficiência visual, é preciso inserir a sala de recursos (que possui como objetivo auxiliar o aluno durante o seu processo de Ensino nas salas regulares), oficinas pedagógicas, recursos tecnológicos adaptados, regletes, sorobans, bengalas, jogos adaptados etc. Os materiais utilizados em sala devem ser fabricados em relevo, para que a criança possa, por meio do tato, internalizar novos conhecimentos. Nesse sentido, Batista et al. (2014, p. 13) afirmam que:

Compreende-se que a criança explora o entorno de maneira fragmentada por meio das mãos e do reconhecimento de fontes sonoras, mas para isso, necessitam comunicar para reunir impressões, identificar os estímulos, interpretar as informações coletadas, estabelecer semelhanças e diferenças, criar esquemas e fazer conexões entre os diferentes componentes e dados das realidades.

Desde cedo é importante proporcionar à criança com deficiência visual a oportunidade de conhecer o mundo em que vive, a partir da sua própria percepção, de forma que possam participar das atividades escolares, mesmo com a sua condição 
visual. Mosquera (2010) enfatiza que a leitura é uma atividade psicológica que cumpre a função social de transmitir informações determinadas culturalmente. Por isso, o Ensino do Sistema Braille é fundamental para os cegos, como meio de leitura e escrita, através de recursos tecnológicos adaptados.

O Sistema Braille foi criado em 1825, por Louis Braille, que também era cego. Trata-se de um sistema de leitura e escrita para pessoas com deficiência visual. Baseia-se na combinação de 63 pontos em relevo, dispostos em duas colunas de três pontos, que representam as letras do alfabeto, os números e outros símbolos gráficos, formando, assim, o que é denominado de cela Braille, sendo lido com a ponta do dedo indicador pressionando os pontos em relevo (MOSQUERA, 2010).

Foi com a Lei $\mathrm{n}^{\circ} 4.169$, de 4 de dezembro de 1962, que foram oficializadas as convenções Braille para uso na escrita e leitura dos cegos, além do Código de Contrações e Abreviaturas Braille. Com a utilização do Sistema Braille, aumenta-se e facilita-se a expansão da comunicação e do expressar. O material adaptado em braile facilita o desenvolvimento da criança na escola. É dever da escola e do Estado garantir o acesso das crianças aos métodos auxiliares de Ensino desde cedo.

O braile deve ser inserido para as crianças antes do momento da alfabetização, pois a criança deve, primeiramente, aprender a ter noção de espaço, de lateralidade e de domínios corporais, pois isso a ajudará a ter domínio sobre a leitura e sobre a escrita nesse sistema (MOSQUERA, 2010). Sá (2007) ressalta que a produção de textos contribui para a estruturação da linguagem e do pensamento, além de despertar a imaginação e a criatividade, como uma situação de aprendizagem muito rica.

A criança com deficiência visual deve participar de todas as atividades propostas, que estimulem a exploração e o desenvolvimento amplo dos outros sentidos, formando uma aprendizagem que tenha significado. Portanto, na ausência da visão, a audiodescrição surge como outro instrumento que deve ser oferecido e utilizado nas escolas. Audiodescrição é um recurso de tradução de imagens em palavras, visando à explicação das imagens, dos objetos, entre outros.

O Atendimento Educacional Especializado é um serviço que deve ser garantido e oferecido em toda e qualquer escola, por professores especializados em atender às crianças com necessidades especiais. Esse atendimento deve ser oferecido em trabalho conjunto com o professor da escola inclusiva, para que juntos possam proporcionar aos estudantes a participação ativa nas atividades escolares. 
Matos (2012) enfatiza a importância da formação de educadores para o atendimento das necessidades educativas de todas as crianças, com ou sem deficiência, tendo em vista a concepção de Educação que respeita a diversidade. Ensinar uma criança com deficiência visual não é tarefa fácil, pois a ausência da visão dificulta o estabelecimento da contextualização do mundo exterior.

É importante lembrar que as pessoas com deficiência visual são capacitadas, com o seu cognitivo perfeito e excelentes ações motoras, e a única dificuldade está na forma que conduzirá e interpretará o mundo. A habilidade para compreender, interpretar e assimilar será ampliada através da variedade de experiências, estimulando o seu desenvolvimento. Masini (1994) enfatiza que, ao interagir, conhecer e explorar, estamos contribuindo para o desenvolvimento de habilidades motoras, equilíbrio, ensinando noções de mobilidade e orientação que ultrapassarão o âmbito escolar. Por isso, é importante destacar que, não se faz necessário supervalorizar ou subestimar a criança com deficiência. Devemos ter em mente que é necessário saber as suas limitações, mas, além disso, saber valorizar as suas potencialidades, que, no caso da cegueira estão relacionadas diretamente às condições estruturais e materiais de acessibilidade.

\section{Conclusões}

Observaram-se com este estudo, avanços no que se refere aos aspectos legais, desde o Decreto ${ }^{\circ} 51.045 / 1961$ até a Lei no ${ }^{\circ} 13.146 / 2015$. A identificação das diretrizes legais acerca da escolarização do aluno com deficiência visual trouxe como aspectos principais: a garantia do acesso e da permanência às escolas inclusivas por todos, independentemente da condição física, intelectual, sensorial ou social; a garantia da acessibilidade. Dentre os aspectos que compõem a garantia da acessibilidade, mereceu destaque o piso tátil, sinalização e alfabetização em braile, Ensino de orientação e de mobilidade e recursos de tecnologia assistiva para atendimento dos estudantes com deficiência visual no contexto escolar.

$\mathrm{Na}$ realização do estudo, houve a reunião de um conjunto de políticas que especificam a necessidade de garantir acessibilidade nas escolas e nos demais espaços públicos. No caso de Manaus, não é possível afirmar que a rede pública municipal de Ensino tenha assegurado esse direito, seja no que denominamos de escolas inclusivas ou escolas exclusivas e de atendimento educacional especializado - AEE. As poucas informações, que agora começam a ser levantadas, demonstram que grande parte das escolas ainda não oferece acessibilidade. Indicam, ainda, que a estrutura de acessibilidade, financiada com verbas públicas federais ou municipais, não atende especificações contidas na própria legislação que the obriga. Logo, apesar dos estudos já realizados sobre a importância da eliminação 
das barreiras arquitetônicas e atitudinais, muitas escolas não oferecem um espaço onde as diferenças e limitações de cada estudante possam ser respeitadas.

Espera-se que esse estudo colabore para reunir um conjunto de informações acerca do atendimento educacional ao deficiente visual, com ideias e conceitos para a efetivação de uma ação educativa inclusiva. Escola inclusiva vai muito além de apenas receber alunos com deficiência: é ter uma estrutura com a qual se possa garantir um bom ensino e uma boa aprendizagem. Portanto, ser inclusiva significa que todos são aceitos, todos fazem parte, todos ajudam e são ajudados. É construir uma sociedade aberta a reflexões, capaz de se definir como agente histórico, participador, autônomo e crítico. 


\section{Visual impairment: legal and theoretical paths of inclusive school}

\section{Abstract}

The article presents results of a research about blindness and low vision in the context of democratization of the access and permanence at school. It is grounded in the historical and legal aspects that mark the paths of public policy in the area, from the analysis of the blindness theme with a focus on accessibility, because the categories of visual impairment and other inclusion issues demand specificities that were not detailed in the research. As it is an exploratory research, the results start from a dense bibliographic research in books and articles that contributed to the comprehension of the theme. Thusly, the formal and legal demands that exist to guarantee access and permanence in schools were identified, as well as the necessary structural conditions to offer this service with a framework in the basic legislation that regulates it. The study also gathers some information from the Municipal Education Department of Manaus, which started in 2017 a mapping of the school structure for accessibility. The cataloged data of the physical structure existing in the schools and made available by the engineering department of the municipal Education department show the complexity surrounding theoretical and practical issues in the democratic context, which supposes the substitution of the concept of an exclusive school for that of an inclusive school, in relation to the care of students with visual impairments.

Keywords: Accessibility. Visual Impairment. Exclusive School. Inclusive School.

\section{Discapacidad visual: caminos legales y teóricos de la escuela inclusiva}

\section{Resumen}

El artículo presenta los resultados de una investigación sobre ceguera y baja visión en el contexto de la democratización del acceso y la permanencia escolar. Parte de los aspectos históricos y legales, que marcan los caminos de las políticas públicas en el área, desde el lema del análisis de la ceguera, con un enfoque en la accesibilidad, ya que las categorías de discapacidad visual y otros problemas de inclusión exigen especificidades que, por el momento, no profundizamos. Como se trata de una investigación exploratoria, los resultados comienzan con una densa investigación bibliográfica en libros y artículos que contribuyeron a la comprensión del tema. Así, se identificaron las demandas formales y legales que existen para garantizar el acceso y la permanencia en las escuelas, así como las condiciones estructurales necesarias para este servicio, con un marco de su legislación básica. El estudio también recopila información de la Secretaría Municipal de Educación de Manaus, que comenzó en 2017 un mapeo de la estructura escolar centrado en la accesibilidad. Los datos catalogados de la estructura fisica existente en las escuelas, y puestos a disposición por el sector de ingeniería de la Secretaría, muestran la complejidad en torno a cuestiones teóricas y prácticas en el contexto democrático que supone la sustitución del concepto de escuela exclusiva por el de una escuela inclusiva, en relación con la asistencia del estudiante con discapacidad visual.

Palabras clave: Accesibilidad. Discapacidad Visual. Escuela Exclusiva. Escuela Inclusiva. 


\section{Referências}

ANACHE, A. A. Educação e deficiência: estudo sobre a educação da pessoa com "deficiência" visual. Campo Grande: CECITEC/UFMS, 1994.

ANACHE, A. A. Deficientes e a educação no Centro-Oeste. In: ZIMERMAN, A. (org.). Ações afirmativas e a educação para pessoas com deficiência. Santo André: Universidade Federal do ABC, 2013.

BATISTA, C. P. et al. A formação docente e a deficiência visual: construindo práticas inclusivas. In: CONGRESSO BRASILEIRO DE EDUCAÇÃO ESPECIAL, 6 ., 2014, São Carlos. Anais[...]. Disponível em: https://proceedings.galoa.com.br/cbee/ autores/claudenilson-pereira-batista?lang=pt-br. Acesso em: 19 jan. 2017

BRASIL. Constituição da República Federativa do Brasil de 1988. Diário Oficial da União, Brasília, DF, 5 out. 1988.

BRASIL. Decreto $\mathrm{n}^{\mathrm{0}} 1.428$, de 12 de setembro de 1854. Crea nesta Côrte hum Instituto denominado Imperial Instituto dos meninos cegos. Coleção de Leis do Império do Brasil, Rio de Janeiro. Disponível em: https://www2.camara. leg.br/legin/fed/decret/1824-1899/decreto-1428-12-setembro-1854-508506norma-pe.html. Acesso em: 25 out. 2017.

BRASIL. Decreto $\mathrm{n}^{\circ}$ 5.296, de 2 de dezembro de 2004. Diário Oficial da União, Brasília, DF, 2 dez. 2004.

BRASIL. Decreto $n^{0} 7.611$, de 17 de novembro de 2011. Dispõe sobre a educação especial, o atendimento educacional especializado e dá outras providências. Diário Oficial da União, Brasília, DF, 18 nov. 2011.

BRASIL. Decreto n ${ }^{\circ} 51.045$, de 26 de julho de 1961. Institui o "Dia do Cego". Diário Oficial da União, Brasíia, DF, 26 jun. 1961.

BRASIL. Lei $n^{\circ} 4.169$, de 4 de dezembro de 1962. Oficializa as convenções Braile para uso na escrita e leitura dos cegos e o Código de Contrações e Abreviaturas Braille. Diário Oficial da União, Brasíia, DF, 11 dez. 1962

BRASIL. Lei n ${ }^{\circ}$ 9.394, de 20 de dezembro de 1996. Estabelece as diretrizes e bases da educação nacional. Diário Oficial da União, Brasília, DF, 23 dez. 1996.

BRASIL. Lei $\mathrm{n}^{\circ} 10.048$, de 8 de novembro de 2000. Dá prioridade de atendimento às pessoas que especifica, e dá outras providências. Diário Oficial da União, Brasília, DF, 9 nov. 2000. 
BRASIL. Lei $\mathrm{n}^{\circ} 10.098$, de 19 de dezembro de 2000. Estabelece normas gerais e critérios básicos para a promoção da acessibilidade das pessoas portadoras de deficiência ou com mobilidade reduzida, e dá outras providências. Diário Oficial da União, Brasília, DF, 20 dez. 2000.

BRASIL. Lei $\mathrm{n}^{\circ} 10.753$, de 30 de outubro de 2003. Institui a Política Nacional do Livro. Diário Oficial da União, Brasília, DF, 31 out. 2003.

BRASIL. Lei no 10.845 , de 5 de março de 2004. Institui o Programa de Complementação ao Atendimento Educacional Especializado às Pessoas Portadoras de Deficiência, e dá outras providências. Diário Oficial da União, Brasília, DF, 8 mar. 2004.

BRASIL. Lei no 11.126, de 27 de junho de 2005. Dispõe sobre o direito do portador de deficiência visual de ingressar e permanecer em ambientes de uso coletivo acompanhado de cão-guia. Diário Oficial da União, Brasília, DF, 28 jun. 2005.

BRASIL. Lei $\mathrm{n}^{\mathrm{o}} 11.982$, de 16 de julho de 2009. Acrescenta parágrafo único ao art. $4^{\circ}$ da Lei $\mathrm{n}^{\circ} 10.098$, de 19 de dezembro de 2000, para determinar a adaptação de parte dos brinquedos e equipamentos dos parques de diversões às necessidades das pessoas com deficiência ou com mobilidade reduzida. Diário Oficial da União, Brasília, DF, 17 jul. 2009.

BRASIL. Lei ${ }^{\circ} 12.527$, de 18 de novembro de 2011. Regula o acesso a informações previsto no inciso XXXIII do art. $5^{\circ}$, no inciso II do $\S 3^{\circ}$ do art. 37 e no $\S 2^{\circ}$ do art. 216 da Constituição Federal; altera a Lei ${ }^{\circ} 8.112$, de 11 de dezembro de 1990; revoga a Lei ${ }^{\circ} 11.111$, de 5 de maio de 2005, e dispositivos da Lei no 8.159, de 8 de janeiro de 1991. Diário Oficial da União, Brasília, DF, 18 nov. 2011.

BRASIL. Lei $\mathrm{n}^{\circ}$ 13.146, de 6 de julho de 2015. Institui a Lei Brasileira de Inclusão da Pessoa com Deficiência (Estatuto da Pessoa com Deficiência). Diário Oficial da União, Brasília, DF, 7 jul. 2015.

BRASIL. Resolução CNE/CEB n ${ }^{\circ}$ 2, de 11 de setembro de 2001. Institui Diretrizes Nacionais para a Educação Especial na Educação Básica. Disponível em: http://portal.mec.gov.br/cne/arquivos/pdf/CEB0201.pdf. Acesso em: 28 mar. 2017.

BRASIL. Resolução CNE/CEB n ${ }^{\circ}$ 4, de 2 de outubro de 2009. Institui Diretrizes Operacionais para o Atendimento Educacional Especializado na Educação Básica, modalidade Educação Especial. Disponível em: http://portal. mec.gov.br/dmdocuments/rceb004_09.pdf. Acesso em: 28 mar. 2017. 
BRASIL. Secretaria de Direitos Humanos da Presidência da República. Secretaria Nacional de Promoção dos Direitos da Pessoa com Deficiência. Cartilha do Censo 2010: pessoas com deficiência. Brasília, DF: CoordenaçãoGeral do Sistema de Informações sobre a Pessoa com Deficiência, 2012.

BRASIL. Secretaria de Educação Especial. Política Nacional de Educação Especial: livro 1/MEC/SEESP. Brasília, DF, 1994.

BRUNO, M. M. G. Educação Infantil: saberes e práticas da inclusão: dificuldades de comunicação sinalização: deficiência visual. Brasília, DF: Secretaria de Educação Especial, 2006.

CONFERÊNCIA MUNDIAL DE EDUCAÇÃO ESPECIAL. Declaração de Salamanca: sobre princípios, políticas e práticas na área das necessidades educativas especiais. Brasília, DF, 1994. Disponível em: http://portal.mec.gov. br/seesp/arquivos/pdf/salamanca.pdf. Acesso em: 30 mar. 2017. (não éBrasil).

COSTA, V. B. Inclusão escolar do deficiente visual no ensino regular. Jundiaí: Paco Editorial, 2012.

INSTITUTO BRASILEIRO DE GEOGRAFIA E ESTATÍSTICA - IBGE. Censo 2010. Rio de Janeiro, 2010. Disponível em: https://censo2010.ibge.gov. br/. Acesso em: 28 jun. 2018.

MACENA, J. O.; JUSTINO, L. R. P.; CAPELLINI, V. L. M. F. O Plano Nacional de Educação 2014-2024 e os desafios para a educação especial na perspectiva de uma cultura inclusiva. Ensaio: Avaliação e Políticas Públicas em Educação, Rio de Janeiro, v. 26, n. 101, p. 1283-1302, dez. 2018. https:// doi.org/10.1590/s0104-40362018002601156

MARQUES, C. A. Integração: uma via de mão dupla na cultura e na sociedade. In: MANTOAN, M. T. E. (org.). A integração de pessoas com deficiência. São Paulo: Menmnon/SENAC, 1997. p.18-23.

MASINI, E. F. S. O perceber e o relacionar-se do deficiente visual: orientando professores especializados. Brasília, DF: CORDE, 1994.

MATOS, M. A. S. (org.). Educação especial, políticas públicas e inclusão: desafios da prática e contribuições da pesquisa no NEPPD/FACED/UFAM. Manaus: Vitória, 2012.

MINAYO, M. C. S.; DESLANDES, S. F.; GOMES, O. C. N. R. Pesquisa social: teoria, método e criatividade. Petrópolis: Vozes, 2015. 
MOSQUERA, C. F. F. Deficiência visual na escola inclusiva. Curitiba: Ibpex, 2010.

SÁ, E. D.; CAMPOS, I. M.; SILVA, M. B. C. Deficiência visual. São Paulo: MEC/SEESP, 2007. (Coleção Atendimento Educacional Especializado).

SÁ, E. D.; SILVA, M. B. C.; SIMÃO, V. S. Atendimento educacional especializado do aluno com deficiência visual. São Paulo: Moderna, 2010.

\section{Informações das autoras}

Fabiane Maia Garcia: Doutora em Educação pela Universidade do Minho, Portugal. Coordenadora do Programa de Pós-Graduação em Educação da Universidade Federal do Amazonas. Contato: fgarciaead@hotmail.com

(iD https://orcid.org/0000-0003-0121-0416

Aissa Thamy Alencar Mendes Braz: Pedagoga pela Universidade Federal do Amazonas. Contato: aissathamy@outlook.com

(iD) https://orcid.org/0000-0001-8608-4492 